\section{Mucocutaneous lymph-node syndrome (Kawasaki disease): probable soluble-complex disorder}

The first description in English of the mucocutaneous lymph-node syndrome (MLNS) ${ }^{1}$ was followed by reports from Hawaii, Canada, the United States, and, recently, Britain. We report a further case.

\section{Case report}

A previously healthy 22-month-old Japanese boy born in Osaka had lived in England for 17 months. He became ill with fever, redness of the hands and feet, and a rash on the trunk and limbs and then developed facial oedema with diarrhoea and vomiting. He was admitted to hospital on the eighth day because of pain and swelling of the neck and inability to swallow.

The patient was feverish, drowsy, and dehydrated, and had neck stiffness, facial oedema, conjunctivitis, cracked, bleeding lips, a red pharynx with prominent tongue papillae, and pronounced cervical adenitis. As the rash faded peripheral oedema became evident and was followed by a striking desquamation of the fingers spreading to the hands and arms. He returned home on the 22nd day, and five days later similar desquamation began on the toes and feet. During the second month we noted a transverse groove on the nails of the fingers and toes. At no time could we detect any abnormality of the cardiovascular system. He was given intravenous fluids and benzylpenicillin for 48 hours followed by cloxacillin for 48 hours until a diagnosis was made on the fourth day. Numerous investigations on blood, urine, cerebrospinal fluid, and faeces failed to yield a pathogenic organism. The table gives the results of haematological studies.

\section{Comment}

The findings in this case were identical with those described in MLNS. Many features of the disease suggest an acute infective aetiology but no consistent pathogen has been isolated. Several immunological changes have been recorded. Increases in serum $\operatorname{IgA}$ and IgM have been observed but no specific immunoglobulin changes were noted until Kusakawa and Heiner reported that the serum IgE was increased in 20 patients during the acute illness and then declined over the next two months. ${ }^{2}$ Raised concentrations of IgE also occur in infantile polyarteritis, and $\mathrm{IgE}$ may play a part (by increasing vascular permeability, thus permitting leucocyte migration and antigen-antibody deposition) in the development of the vasculitis. There is no evidence that children with pre-existing high concentrations of IgE are particularly susceptible to MLNS, and family studies have not shown an increased incidence of allergic disorders. Our patient's IgE concentration was in the upper normal range during the acute phase of the illness and declined on recovery.

Changes in serum $\mathrm{C} 3$ have been noted in two patients. A reduced concentration was recorded on day 7 in one ${ }^{3}$ and a raised value at an unspecified time in another. ${ }^{4}$ Transient changes in serum complement concentrations may be expected in MLNS as in other acute illnesses, and repeated estimations are required to determine their significance. Our patient had low concentrations of both haemolytic complement $\left(\mathrm{CH}_{50}\right)$ and $\mathrm{C} 4$ on day 12 of the illness and increased concentrations of $\mathrm{CH}_{50}, \mathrm{C} 4$, and $\mathrm{C} 3$ during recovery. In addition the platelet aggregation test for detecting circulating immune complexes ${ }^{5}$ gave a strongly positive result on day 12 , the activity declining to normal during recovery.
Although these observations require confirmation, the changes were similar to those found in other immune-complex disorders. Circulating immune complexes and increased concentrations of $\operatorname{IgE}$ possibly play a part in the pathogenesis of MLNS and may be responsible for the major complications.

We thank the consultants in this case, Dr A M Geddes and Dr M J Tarlow, for helpful advice and criticism.

Kawasaki, T, et al, Pediatrics, 1974, 54, 271.

${ }^{2}$ Kusakawa, S, and Heiner, D C, Pediatric Research, 1976, 10, 108.

${ }^{3}$ Melish, E, Hicks, P M, and Larson, E, American Fournal of Diseases of Children, 1976, 130, 599.

${ }^{4}$ Brown, J S, et al, fournal of Pediatrics, 1976, 88, 81.

${ }^{5}$ Myllylä, G, Scandinavian fournal of Haematology, 1973, suppl No 19.

(Accepted 24 February 1977)

East Birmingham Hospital, Birmingham B9 5ST

C FOSSARD, MSC, MRCP, senior registrar in paediatrics R A THOMPSON, MRCP, MRCPATH, consultant immunologist

\section{Case of Kawasaki disease}

In 1967 Kawasaki described 50 Japanese children with a febrile condition that he called the mucocutaneous lymph-node syndrome (MLNS). Though it resembles the Stevens-Johnson syndrome, genital lesions do not occur and the stomatitis and conjunctivitis are not associated with vesiculation or pseudomembrane formation. In $1974 \mathrm{Kawasaki}^{\text {et }}$ al $^{1}$ detailed the clinical and epidemiological features. The disease appeared to be confined to Japan until Melish et al ${ }^{2}$ reported nine cases in multiracial children in Hawaii. Further reports have come from the USA, South Korea, Greece, Australia, and, recently, Britain. Japanese workers regard the condition as a disease entity and refer to it as Kawasaki disease.

I report a possible case of the disease in a child admitted to this hospital in July 1975.

\section{Case report}

A 5-year-old girl of Italian parentage who had lived in England since birth was seen with a 12-hour history of abdominal pains and vomiting. Fever and bilateral ocular congestion were noted. The vomiting settled within 24 hours. On the second day she started a course of amoxycillin. She then had circumoral redness, which, together with fever, persisted until admission two weeks later. A week before admission pronounced redness of the hands and feet developed, with desquamation starting the next day.

On admission she was found to be a well-nourished, febrile girl with a pulse rate of $136 / \mathrm{min}$. The circumoral skin was erythematous and cracked, and yellow crusting was noted. She had stomatitis, and her tongue was partly coated with white plaques. Upper cervical lymph nodes were enlarged and tender. There was palmar and volar erythema, with desquamation occurring

Results of haematological investigations during illness

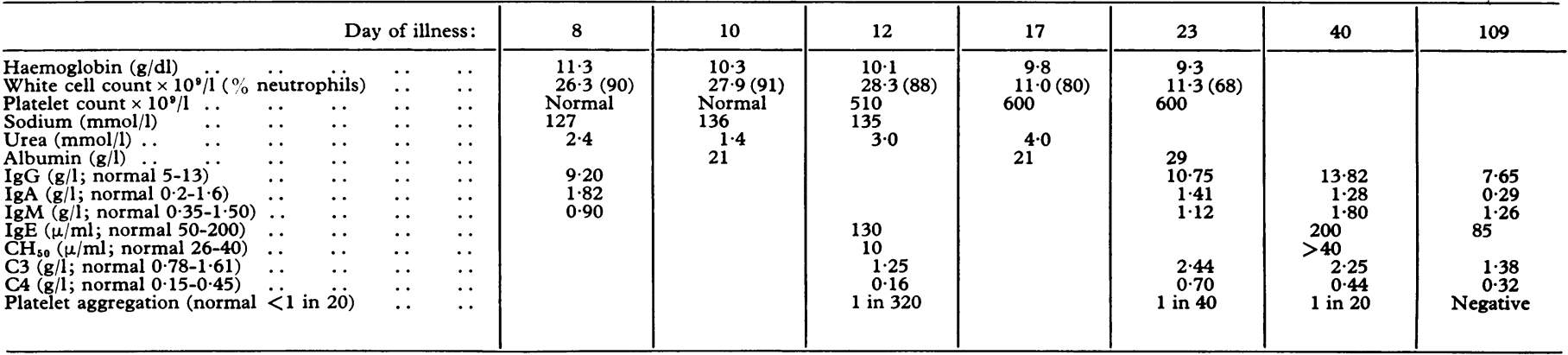


particularly around the terminal phalanges. Auscultation of the heart showed no abnormality.

Erythrocyte sedimentation rate was $45 \mathrm{~mm}$ in the first hour; urine contained $1 \mathrm{~g}$ protein $/ \mathrm{l}$, three red cells and five leucocytes per high-power field, and some cellular casts; and mouth culture yielded a small growth of Candida, and facial swabs a mixed growth of organisms. The table lists the serological titres. An electrocardiogram showed sinus tachycardia and a prolonged corrected Q-T interval of $0.4 \mathrm{~s}$ but was normal three weeks later. Full blood count, plasma urea and electrolytes, serum alanine and aspartate transaminases, plasma proteins, and a chest radiograph were all normal.

The fever settled spontaneously next day but the tachycardia persisted, slowing to $100 / \mathrm{min}$ over the five days' stay. With resolution of the fever a pleomorphic erythematous rash developed on the trunk and lasted less than 24 hours. The facial rash became more impetiginous, and she was discharged taking flucloxacillin. Two weeks later the facial rash had healed and minimal palmar desquamation was present.

Acute and convalescent serological titres in patient with MLNS

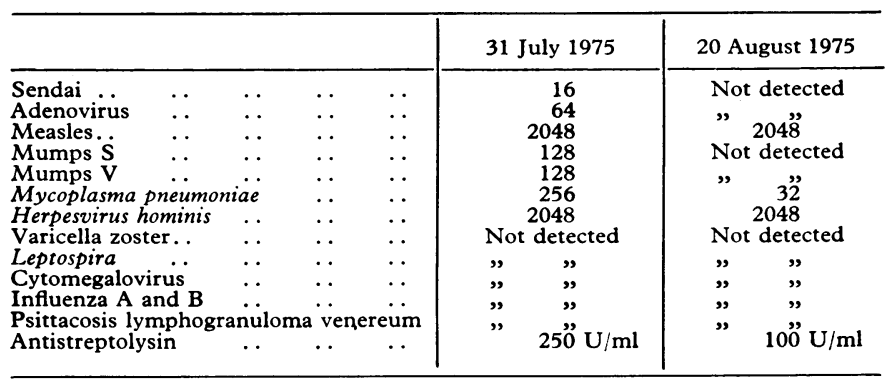

\section{Comment}

This patient showed all the principal features of Kawasaki disease except indurative oedema and "strawberry tongue." Up to $70 \%$ of the patients with the disease have evidence of myocarditis, ${ }^{3}$ and this patient was no exception. Although complete recovery is usual, 1-2\% of children with the disease die suddenly, necropsy showing myocardial infarction with obliteration of the coronary arterial lumen and periarteritis nodosa. ${ }^{4}$ Coronary aneurysms have been detected in some survivors. Renal impairment with proteinuria and leucocyturia occurs and was present in this patient.

The cause of Kawasaki disease is unknown. The aetiology was discussed by Goldsmith et $a l,{ }^{5}$ who reported a case in an American child. Recognition of the disease would prevent unrewarding invasive investigations such as lymph-node biopsy being carried out and enable an informed opinion on prognosis to be given.

I thank Professor D Hull for help in writing this report, and Miss Salome Anderson for secretarial work.

\section{Kawasaki, T, et al, Pediatrics, 1974, 54, 271}

${ }^{2}$ Melish, M E, Hicks, R M, and Larson, E, Pediatric Research, 1974, 8, 427.

3 Asai, T, et al, Fapanese fournal of Pediatrics, 1973, 26, 284.

4 Yanagisawa, M, Kobayashi, N, and Matsuya, S, Pediatrics, 1974, 54, 277.

5 Goldsmith, R W, Gribetz, D, and Strauss, L, Pediatrics, 1976, 57, 431.

(Accepted 2 March 1977)

Nottingham Children's Hospital, Nottingham NG3 5AF

C J HEWITT, MB, MRCP, senior registrar

\section{Recurrence of Gilles de la Tourette syndrome}

The syndrome of Gilles de la Tourette ${ }^{1}$ is a rare triad of (1) explosive involuntary utterances including inarticulate noises and explicit obscenities (coprolalia); (2) multiple motor tics; and (3) onset in childhood or adolescence (below the age of 16). A fourth feature often noted is imitative phenomena, ${ }^{2}$ which are also involuntary with obsessional qualities. It is commoner in males.
The present case is reported because of its unusual, episodic course and because of the close association of the renewed symptoms with psychological stress.

\section{Case report}

A 29-year-old married woman was informally admitted in October 1974. She had been adopted at the age of 6 weeks and was the only child reared by her adoptive parents. At the age of 5 she started to compulsively repeat sounds and when 8 began to blink and grimace. She had been very "clinging" to her mother and aged 9 had stayed at home for two months because of fear of leaving home. She had suffered from "asthma" between her second and fifth years. The facial tics and compulsive utterances receded when she was 11 and she remained symptom-free until the development of her current symptoms. Four months before admission she began to scream and to repeat noises, words, or parts of words which she had heard on television. Initially she screamed infrequently "just to relieve tension" but as time progressed she "barked" and made other bizzare noises daily. On the day of admission "a barking attack" lasting for an hour ended when her husband contacted their family doctor.

She described her symptoms as follows: "I'm obsessed with wanting to make as many sounds as possible; I dread going anywhere and being in company because I will start making these sounds-I will be silly and make a terrible fool of myself." She complained of being unhappy, of having lost confidence, and of having no interest in her home. The multiple tics, which consisted of blinking of both eyes, raising the left side of the mouth, and shrugging her shoulders, did not concern her. (They began shortly after her abnormal vocalisations.)

The sounds took the form of vowels of one syllable- "aou-ee-u" and were usually repeated staccato-like in bursts of one to five seconds. No complete words or obscenities were heard. She was pleasant and articulate and could not explain the form her symptoms took. The first symptoms had been the depressive ones and had been precipitated by a series of unsatisfactory events. A daughter had nearly died from pneumonia; her husband had developed a heart condition; he had incurred debts of $£ 150$ through gambling; and the family were facing eviction.

Reactive depression and Gilles de la Tourette syndrome were diagnosed. Counselling of the couple was undertaken to facilitate more effective coping and tryptizol, $25 \mathrm{mg}$ thrice daily and at night, was prescribed. The vocalisations ceased within two weeks and she was discharged after one month. Her tics ceased within three months and her medication was discontinued shortly afterwards. She has been symptom-free for 18 months. The results of routine laboratory and radiological investigations were all normal, as was an electroencephalogram. Psychological assessment showed a full scale IQ (WAIS) of 105. Personality inventories (16PF, DPI, HDHQ) indicated a highly developed sense of duty; shyness; a tendency to seek few but warm relationships; above average self-directed hostility and lack of oral aggression; and some rigidity. The results of diagnostic tests (MMPI, Beck Inventory) were consistent with the presence of mild depression.

\section{Discussion}

The 18-year remission in this case is unusual. Most cases run a continuous course with an early development of tics followed several years later by abnormal vocalisations. ${ }^{3}$

The present episode seemed related to considerable social distress, a pattern already reported, and not uncommon in other neuropsychiatric conditions. Anxiety or depression commonly precedes the neurological changes of Huntington's chorea, ${ }^{4}$ while depression may accompany Parkinsonism. Though haloperidol is regarded as its most effective treatment, Fernando has commented that the management of the syndrome "should be sufficiently flexible to be geared to the individual patient's needs at any particular time"-a view that could be usefully applied in the management of other neuropsychiatric conditions.

I would like to thank Dr J E Duffield and Dr A D Harris of Littlemore Hospital, Oxford, for permission to report this case and Mrs $\mathrm{K}$ Jambor for completing the psychological testing.

1 Gilles de la Tourette, Archives de Neurologie, 1885, 9, 158.

2 Woodrow, Kenneth, M, American fournal of Psychiatry, 1974, 131, 1000.

3 Shapiro, A K, et al, Psychosomatic Medicine, 1973, 35, 431.

${ }^{4}$ Dewhurst, Kenneth, et al, British fournal of Psychiatry, 1970, 116, 255.

${ }^{5}$ Fernando, S J M, British Fournal of Psychiatry, 1976, 128, 439.

(Accepted 13 December 1976)

\section{Department of Psychiatry, University of Oxford}

P A CARNEY, MRCPSYCH, DPHIL, lecturer (present address: Department of Psychiatry, University College, Galway) 